\title{
Reliability of Excavators At "Baganuur" Coal Mine
}

\author{
LkhamjavOrkhon*, AltankhuyagAriunbold** \\ Mongolian National University \\ Orkhon_Lkha@yahoo.com
}

\begin{abstract}
The results of the study of operational reliability of the draglines in Baganuur coal mine for 25-30 years of their exploitation;- Analysis of changes in the specific total duration of repairs and curve approximation of the dependence on the lifetime;-Conclusion about the need to define the rational lifetime and to maintain higher level of reliability and efficiency of draglines by using vibro-diagnosis.
\end{abstract}

Keywords:reliability, lifetime, specific total duration of unscheduled repairs etc.

\section{Introduction}

The mining industry has a leading position in the economy of Mongolia. The industry not only provides with coal the heat electro-power stations II,III,IY and Darkhan and Erdenet, but also exports gold, fluorite, coking coal which affects the growth of the country's gross output. Therefore, the economic development of the country largely depends on the efficiency of the mining industry.Currently, the mining of mineral resources in Mongolia mainly executed by open pit and the mines use the Russian excavators such as EKG-5A, EKG-4U, EKG-8I, EKG-10, ESH-10.70, ESH-20.90, ESH-13.50 and ESH-15.90. These engines mainly exploited in Baganuur coal mine. Their age is between 21-30 years. It should be noted that the study of exploitation of these excavators conducted inadequate until today.

The delays of machines in scheduled and unscheduled repairs reach up to $30 \%$ of the total fund of calendar year and the operating efficiency and availability ratio are within $0.65-0.89$. The open-mine excavators work in harsh extreme continental climate with large fluctuations in the outside temperatures from -50 to $+40^{\circ} \mathrm{C}$ and wind speed of $10-20 \mathrm{~m} / \mathrm{s}$. All this causes the additional dynamic loads in the main units of machines which lead to the intensive deterioration of equipment.One of the methods to improve the efficiency of the use of highpower high-performance machines can be a timely and rapid assessment of the technical state of excavators with minimal time to repair service.In connection with this diagnosis and assessment of the technical state of equipment is one of the main priority issues. According to the observation of the work of the EKG-8I and EKG5A mine excavators during 2003-2011 years their levels of reliability depending on their lifetime have been evaluated.To assess the reliability of these machines we have taken availability ratio, technical utilization rate, the specific total duration of repairs. Thus, thespecific total duration of repairs for each age group of excavators defined according to statistics by the following formula:

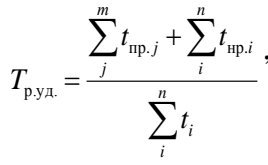

where $\sum_{i}^{n} t_{i}$-total annual operating times of excavators within one age group, $i=1 \ldots m, \mathrm{~h}$;

$\sum_{j}^{m} t_{\text {пр. } . j}-$ total annual duration of scheduled repairs of excavators within one age group, $j=1 \ldots m, \mathrm{~h}$;

$\sum_{i}^{n} t_{\text {нр. } i}$-total annual duration of unscheduled repairs of excavators within one age group, $i=1 \ldots n, \mathrm{~h}$;

$m$ m $n$-number of scheduled and unscheduled repairs $[1,2,3,4,5]$

Main mechanisms of excavator ESH-20.90 used in Baganuur coal mine

I.

\begin{tabular}{|l|l|l|l|}
\hline Excavator's model & Main mechanisms & Failure ratio & Downtime ratio \\
\hline ESH-20.90 & Working equipment & 0,192 & 0,25 \\
\cline { 2 - 4 } & Hoisting mechanism & 0,108 & 0,16 \\
\cline { 2 - 4 } & Traction mechanism & 0,23 & 0,19 \\
\cline { 2 - 4 } & Swing-out mechanism & 0,15 & 0,17 \\
\hline
\end{tabular}


\begin{tabular}{|l|l|l|l|}
\hline & Walking mechanism & 0,07 & 0,10 \\
\hline
\end{tabular} Key indicators of reliability of excavator ESH-20.90 used in Baganuur coal mine

\begin{tabular}{|c|c|c|c|c|c|c|c|}
\hline & & & & & si & & \\
\hline Excavator's model & 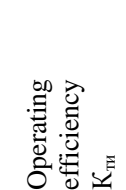 & 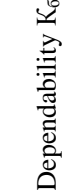 & 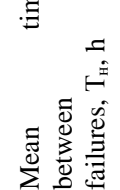 & 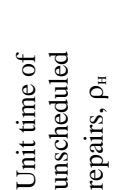 & 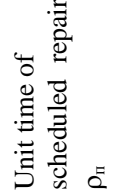 & 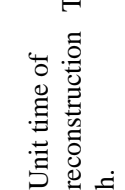 & 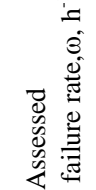 \\
\hline ESH-20.90 & 0,61 & 0,84 & 104,3 & 0,19 & 0,25 & 8,5 & 0,0073 \\
\hline
\end{tabular}

Mean time between failures and average time of reconstraction are different which gives the possibility to increase the reliability indicators of excavators[1], [2], [4], [6].Even though, the availability and technical application are higher than other basic devices, the average time of reconstruction 80-104 hours represents the possibility to reduce the duration of scheduled and unscheduled repairs and maintenance.Therefore, the calculation of the reliability indicators of excavators and the use of the distribution law allow to precise the maintenance planning. Reliability indexes defined for each age group of machines, depending on their lifetime.

To determine the dependence of specific total duration of repairs, availibility ratio and technical application on their lifetime, there have been created relevant samples of input data processed by special program StatSoft that generated analytical dependence and relevant correlation ratio [2, 3].Picture I shows the change of specific total duration of repairs of excavators $K_{\text {уд }}$ EKG-5A during 2003-2011. Approximation equation obtained for $\mathrm{K}_{\text {уд }}$ with a correlation ratio $\mathrm{R}=0,47$ shows a trend of steady increase in the average value of the reliability index from 0.12 to 0.29 , ie 2.4 times during the lifetime.

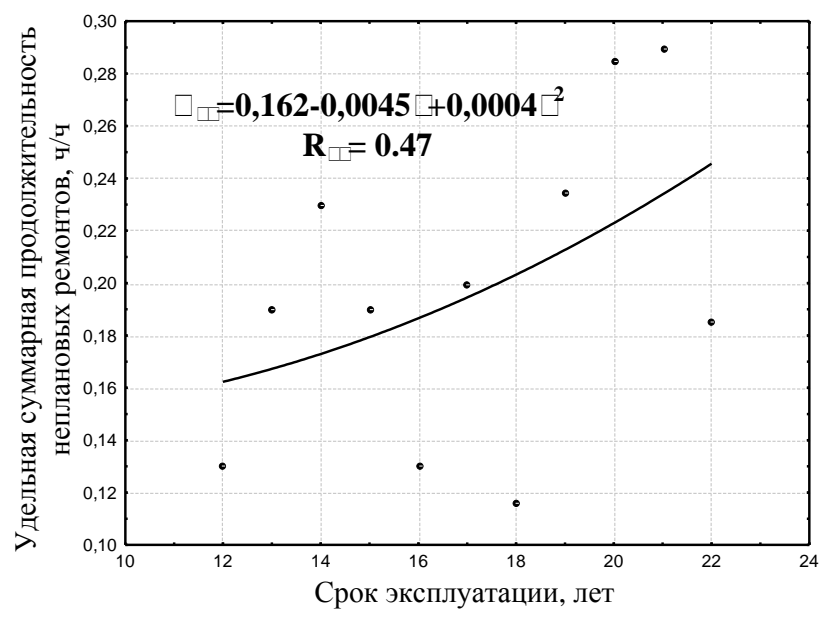

Pic. I.Dependence of specific total duration of repairs ofexcavators EKG-5A on their lifetime.

Picture II represents the change of specific total duration of repairs $K_{\text {уд }}$ of excavators EKG-8I during 2003-2011. Comparing with the excavator EKG-5A, the character of change shows a clear tendency of steady increase from 0.13 to 0.40 (correlation ratio $\mathrm{R}=0.48$ ) i.e. 3 times.

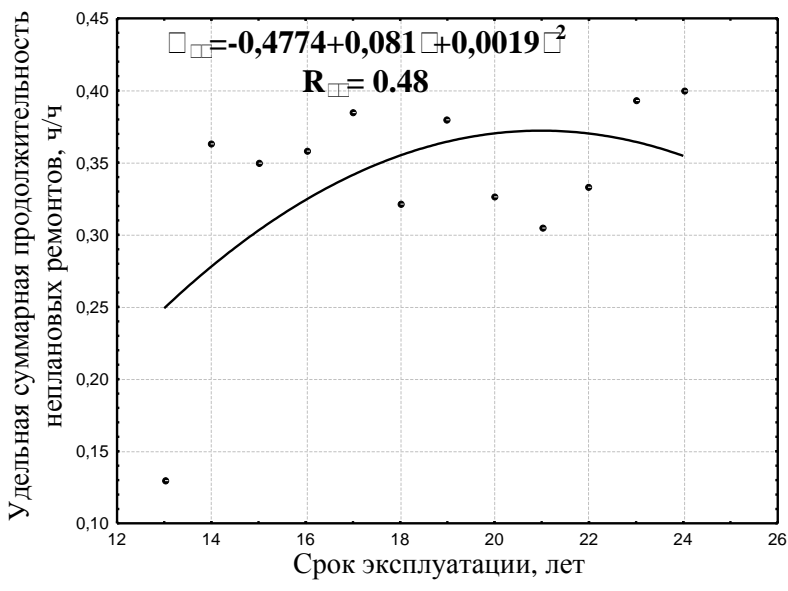

Pic.II.Dependence of specific total duration of repairs ofexcavators EKG-8I on their lifetime. 
The specific total duration of repairs of excavators-draglines also have a tendency of increase during 2003-2011 (pic.III). Curves approximation shows that the average values of reliability index increased in 12 years of operation of machines from 0.12 to 0.34 , i.e, almost 3 times (correlation coefficient $\mathrm{R}=0,71$ ).

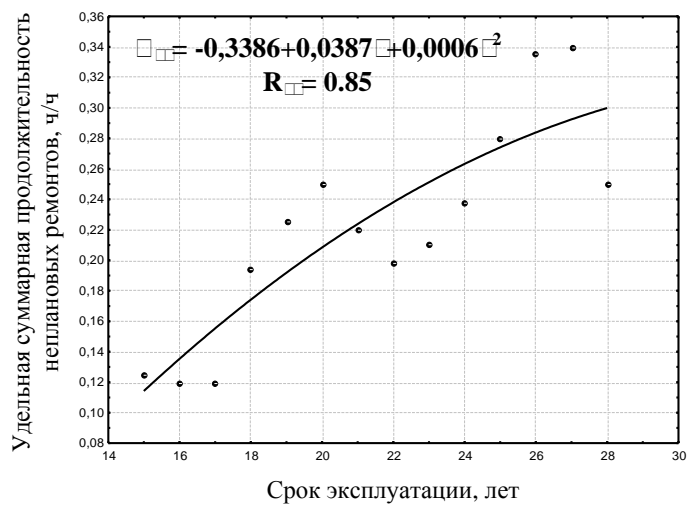

Pic. III.Dependence of specific total duration of repairs of Excavators-draglines on their lifetime.

The dependences obtained indicate that an increase in lifetime of machinery and equipment has been steadily declining their technical condition. This is due to the growth of both planned and unplanned downtime in repairing machines, thereby reducing the level of its reliability, increasing downtime and repair costs, and reducing the production capacity of machines. As the lifetime of excavators is extended, the level of operational reliability is reduced and the cost of time and material and technical resources for maintenance and repair is increased.The experiment established the laws of the distribution of time between failures of major components of excavators[1]. As an example, the picture IY and Y represent the experimental and theoretical distribution of mean time between failures of lifting reducers and traction gear box of excavator ESH-20.90.

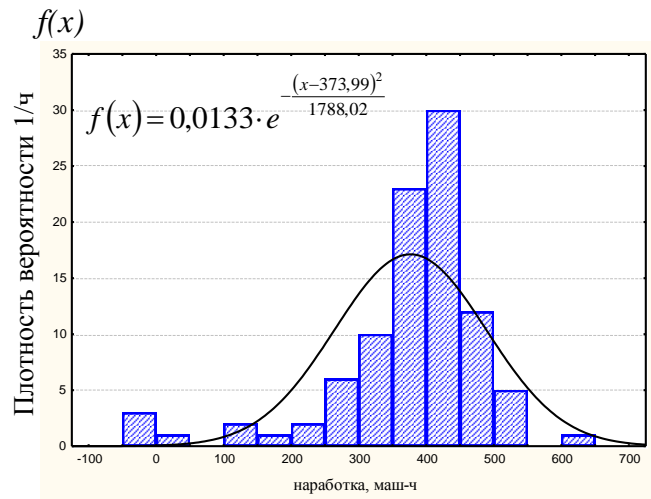

Pic.IY.Experimental and theoretical distribution of mean time between failures of lifting reducers ESH-20.90

It was found that the distribution of the operating time between failures of the traction gear and lifting reducers of excavator ESH-20.90 corresponds to the normal law.

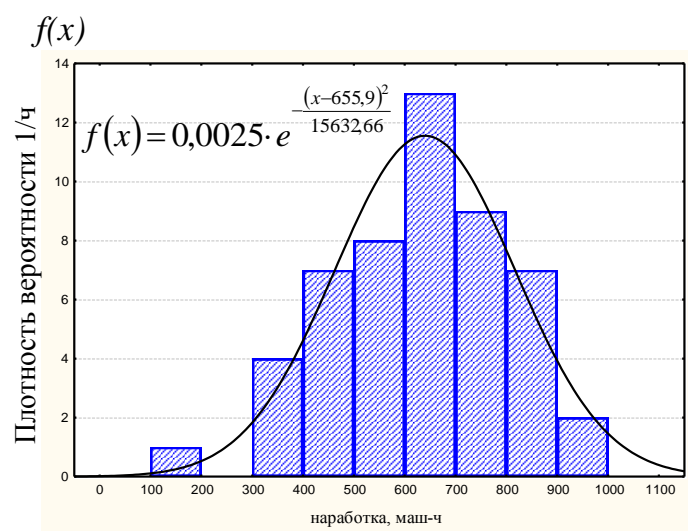

Pic. Y.Experimental and theoretical distribution of mean time between failures of the traction gear box of ESH20.90 . 


\section{Conclusion}

Results of the study can be used in forecasting the level of reliability, the development of maintenance and repairs regulations, as well as when planning production capacity of excavators at "Baganuur" coal mine.A significant reduction in the level of reliability is due to the low level of maintainability of equipment, as well as the imperfection of the existing system of maintenance and repairs. And this is compounded by a long lifetime of equipment and large depreciation of vehicles in extreme conditions. The low level of reliability causes a problem to shorten the lifetime due to the high cost of maintenance of machines. And to improve the maintainability of excavators there is a need to implementthe vibration methods of condition monitoring of gearboxes and traction lift.

\section{References}

[1]. Orkhon L. "Justification of regulations of maintenance and repair of rotary units of draglines by vibration features" doctoral dissertation, Irkutsk, Russia, State Technical University of Irkutsk, 2013;

[2]. Ts. Nanzad "Theory and methods of the study of reliability of Excavators"

[3]. Shadrin A.I. "Reliasbility of mining machinery and equipment", Irkutsk, Russia, State Technical University of Irkutsk, 2012. p.160;

[4]. Shadrin A.I. "Technical exploitation of mining machinery and equipment". Irkutsk: Russia, State Technical University of Irkutsk, 2012. - p.320;

[5]. Machno D.E "Maintenance and repair of mechanical excavators in the North": handbook, /Machno D.E., Shadrin A.I. - M.:Subsoil, 1992. - p.127. 